\title{
PROGRAM HOLISTIK PEMBANGUNAN PEMBERDAYAAN DESA (PHP2D) OPTIMALISASI BALAI BANJAR SEBAGAI RUMAH BELAJAR PADA MASA COVID 19 DI DESA CEPAKA TABANAN
}

\author{
Ni Luh Putu Agustini Karta ${ }^{\left.1^{*}\right)}$, I Ketut Sutapa ${ }^{2}$, Rani Kusumo Wardani ${ }^{3}$ dan \\ Erna Wiles ${ }^{4}$ \\ (Universitas Triatma Mulya ${ }^{\mathbf{1 , 2 , 3 , 4}}$ ) \\ agustini.karta@triatmamulya.ac.id ${ }^{*}$
}

\begin{abstract}
The Covid 19 pandemic has weakened the economy of the world community. The resulting impact is felt by all levels of rural and urban society; among parents, adults and children. Amid the economic downturn, people must survive. Various alternative efforts were made so that people could still eat and receive education. Especially school children who are very risky if their education is stopped for a relatively long time. This condition motivates the HIMA Accounting and Management of Triatma Mulya University to implement the PHP2D program through the optimization of the Banjar Hall as a Learning Center in the Covid 19 Pandemic Era in Cepaka Village, Tabanan, Bali. used as an arena for monthly meetings. Through this PHP2D program, the Banjar Hall is now equipped with internet facilities, work desks and bookshelves for libraries. Every day at 15-18 wita the children in each banjar; come to study with the help of students and lecturers. The availability of free internet and the presence of 5 students as teachers / mentors in each banjar make a positive contribution to the community and children in Cepaka village. After four months of this activity, a very harmonious relationship was formed between students and school children ranging from elementary and junior high schools. School children, totaling nearly 150 children, are trained in their learning, academic, soft skills and hard skills in order to grow into a superior generation. This activity received a warm welcome from the community, even the Head of Kediri Sub-district was very grateful and made Cepaka Village the first project pilot village to provide a learning house with free wi-fi. It is hoped that in the next period other villages can also be developed, students help children in learning so that they can achieve their goals.
\end{abstract}

Keywords: banjar, learning house, Covid 19.

\section{PENDAHULUAN}

Sebelum
mengajukan
mahasiswa
melakukan survey pada Desa Cepak
untuk melihat dampak Pandemic
Covid 19 terhadap proses belajar
anak-anak. Kegiatan survey awal
dilakukan secara kuantitatif dan
kualitatif; dibagi menjadi 4 aspek
yakni:

1) Survey kualitatif terhadap aparat desa tentang sumber daya alam, ekonomi dan sumber daya manusia, profil dan potret desa Cepaka.

2) Survey secara kualitatif melalui wawancara dengan kepala desa Cepaka tentang pendanaan operasional desa, prioritas dan 
implementasinya.

3) Survey kuantitatif terhadap masyarakat desa melalui google form tentang implementasi pembelajaran di sekolah dasar di desa Cepaka dan sekelumit permasalahannya.

4) Survey kualitatif tentang animo belajar siswa dan metode pembelajaran siswa di desa semasa pandemic.

Hasil survey kuantitatif dan kualitatif melalui wawancara dengan aparat desa Cepaka, tersirat bahwa berbagai permasalahan yang terjadi di desa Cepaka membutuhkan solusi segera; yang salah satunya berbentuk program pemberdayaan melalui pembentukan rumah belajar program PHP2D. Hasil survey diatas menjadi latar belakang utama para mahasiswa untuk melaksanakan program rumah belajar dengan memanfaatkan dana dari Kementerian Pendidikan dan Kebudayaan. Wawancara dengan kepala desa Cepaka, Drs. I Ketut Tedja, MSi. Menjelaskan bahwa selama ini banyak orang tua yang mengeluh; putra putrinya bersekolah di SD Cepaka, tiap hari tidak cukup guru yang mengajar. Baik guru tetap maupun guru honorer. Wabah Covid 19 menjadikan proses belajar dan mengajar terhenti total. Ibarat kata pepatah "gayung bersambut, kata berjawab". Kehadiran tim Himpunan Mahasiswa Akuntansi Manajemen (HIMA) Universitas Triatma Mulya melalui program PHP2D sangat ditunggu oleh masyarakat dan aparat desa setempat.

\section{Perumusan Masalah}

Fokus program pemberdayaan adalah pada aspek pendidikan yakni peningkatan kualitas sumber daya manusia melalui pembentukan rumah belajar, perpustakaan serta pengembangan UKM. Berdasarkan hasil survey yang dilakukan terhadap masyarakat desa Cepaka, maka rumusan masalah dapat dijabarkan sebagai berikut:

1) Bagaimana pengadaan perpustakaan di balai banjar berkontribusi membantu meningkatkan semangat belajar anak-anak sekolah di Desa Cepaka pada masa pandemic Covid 19 ini?

2) Bagaimana pemasangan jaringan internet dan manajemen belajar yang akan dilaksanakan di banjarbanjar sebagai rumah belajar di desa Cepaka, oleh mahasiswa UNTRIM dapat meningkatkan capaian pembelajaran anak-anak selama Covid 19?

3) Bagaimana tim mampu melaksanakan program secara holistik dengan prioritas utama pada pembelajaran anak-anak pada masa pancemic Covid 19?

\section{Tujuan Pelaksanaan Program}

Berdasarkan hasil survey dan observasi sebelum pandemic covid 19, di balai banjar dan balai desa Cepaka belum ada internet. Wajarkah kita menuntut kualitas pembelajaran dan hasil pembelajaran yang bagus? Kemudian muncul wabah covid 19 , maka semakin memprihatinkan kondisi anak didik di desa Cepaka. Mempertimbangkan program PHP2D Dikti diselanggarakan untuk mengatasi permasalahan teknis di desa yang terkendala karena Pandemic Covid 19, maka tujuan dari program pemberdayaan ini dideskripsikan sebagai berikut:

1) Mensolusi keterbatasan pembelajaran dengan membangun perpustakaan di balai banjar. Manajemen buku, asistensi belajar di balai banajr oleh mahasiswa 
UNTRIM diharapkan mampu membantu anak-anak sekolah dalam belajar selama pandemic Covid 19.

2) Memperluas literasi belajar anakanak sekolah melalui pemasangan akses internet di desa, banjarbanjar. Melalui mekanisme manajemen belajar di banjarbanjar sebagai rumah belajar di desa Cepaka, diharapkan dapat meningkatkan hasil pembelajaran anak-anak.

3) Program yang dilaksanakan agar terintegrasi dan holistik dengan memprioritaskan aspek-aspek utama yakni pengembangan kualitas sumber daya manusia desa.

\section{Manfaat Kegiatan di Waktu Mendatang}

Secara lebih rinci manfaat program PHP2D saat ini maupun untuk waktu mendatang dapat dijelaskan sebagai berikut:

a) Menumbuhkan kembali semangat belajar anak-anak sekolah yang sempat terhenti pada masa Pandemik Covid 19.

b) Meningkatkan kebersamaan, interaksi social, kemampuan berkomunikasi anak-anak sekolah yang selama ini kurang mendapat perhatian dari guru-guru di sekolah mereka. c) Meningkatkan kreatifitas dan rasa peduli kepada lingkungan sekitar dan memahami kondisi Covid 19 yang menuntut mereka harus sadar dengan hidup sehat, rajin cuci tangan, jaga jarak dan membatasi kegiatan berkumpul.

d) Kegiatan PHP2D ini juga menjadi ajang pengganti rasa kangen dunia anak-anak yang hamper setahun ini terlindas oleh Covid 19. Walaupun hanya 2 jam, namun sangatlah berarti bagi anak-anak sekolah.

e) Di masa mendatang kegiatan ini akan tetap dilaksanakan oleh mahasiswa UNTRIM bekerjasama denagn para relawan yang ada di desa.

f) Setelah projek PHP2D selesai, kepala desa akan tetap menyelenggaran rumah balajar di balai banjar, menetapkan jam wajib belajar anak-anak di balai banjar dengan membunyikan kentongan tanda waktu belajar setiap jam 16 sampai jam 18 WITA.

\section{Kondisi Masyarakat Sasaran}

Masyarakat sasaran program PHP2D ini terdiri dari berbagai elemen dengan volume permasalahan yang harus diatasi; dijabarkan pada Tabel 8 berikut ini:

Tabel 1

Kondisi Masyarakat Sasaran

\begin{tabular}{lll}
\hline NO & \multicolumn{1}{c}{ MASYARAKAT SASARAN } & \multicolumn{1}{c}{ KETERANGAN } \\
\hline 1 & Jumlah khalayak sasaran anak-anak usia sekolah & $100-120$ orang \\
2 & Jumlah total orang desawa yang terlibat & $50-75$ orang \\
3 & Tokoh masyarakat yang terlibat (Kades dan & 20 orang \\
& aparatnya, tokoh adat dan agama, kelian banjar) & \\
4 & Jangkauan kegiatan dan luas lahan & Satu desa 200 Ha \\
5 & Jumlah kelompok kegiatan utama & 20 aktivitas \\
6 & Karateristik masyarakat sasaran & $\begin{array}{l}\text { Anak-anak, orang tua /dewasa, } \\
\text { petani, pengelola UKM }\end{array}$ \\
\hline
\end{tabular}




\section{METODE PELAKSANAAN \\ Metode Pelaksanaan}

Metode pelaksanaan kegiatan pemberdayaan masyarakat adalah dengan kombinasi antara online dan offline. Road Map Teknis pelaksanaan kegiatan dijabarkan pada Tabel 9 berikut ini:

\section{Tabel 2}

Metode Pelaksanaan Kegiatan

\begin{tabular}{ll}
\hline NO & \multicolumn{1}{c}{ KEGIATAN } \\
\hline 1 & Peningkatan kualitas dan manajemen \\
& perpustakaan \\
& 1) Pengadaan rak buku \\
2) Pengumpulan buku-buku \\
3) Pembuatan katalog buku \\
4) Pembuatan sistem kontrol buku \\
5) Pendampingan belajar di \\
\end{tabular}

Juli - Agustus

2 Pengadaan akses internet di banjar, dan sekolah SD serta PAUD

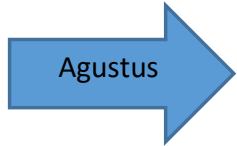

3 Penyelenggaraan rumah belajar digital di banjar.

1) Pemperkenalkan metode belajar

2) Pembagian kelas belajar

3) Pendampingan belajar

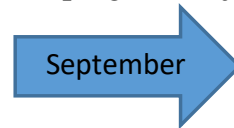

4 Pendampingan anak-anak belajar

1) Afektif pada setiap banjar

2) Terjadwal dengan baik pada setiap banjar

3) Berkelanjutan pada setiap banjar

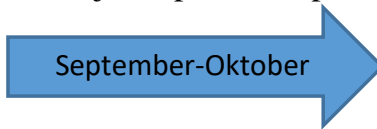

5 Evaluasi dan Pelaporan
1) Menyiapkan laporan
2) Publikasi
3) Koordinasi keberlanjutan program

TEKNIS PELAKSANAAN P I C

Dosen dan

1) Langsung

2) Langsung

3) Langsung

4) Langsung

5) Langsung dan diatur dalam kelompok kecil sesuai protokol kesehatan

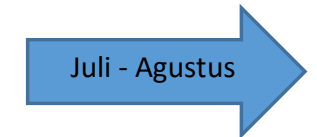

Langsung

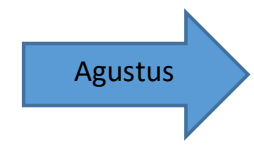

Langsung dan atau daring

1) Langsung (kelompok kecil)

2) Langsung (kelompok kecil)

3) Langsung (kelompok kecil)

$$
\text { September }
$$

Mahasiswa

Mahasiswa

Mahasiswa

Mahasiswa

Mahasiswa

Mahasiswa

Juli - Agustus

Dosen, aparat dan teknisi.

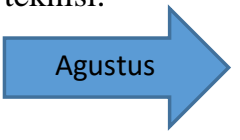

Dosen dan

Mahasiswa

Mahasiswa

Mahasiswa

September

Langsung dan atau daring

Dosen dan

Mahasiswa

1) Dilaksanakan pada setiap banjar

Mahasiswa

Mahasiswa

November

September-Oktober

Langsung atau daring

Dilanjutkan

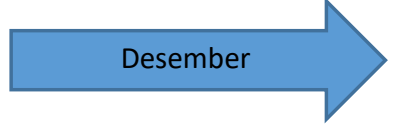

Januari 


\section{HASIL DAN PEMBAHASAN Hasil Implementasi Pembelajaran PHP2D}

Dari perspektif masyarakat sasaran, program ini memberi kontribusi yang cukup berharga dan membangkitkan semangat belajar anak-anak dan orang tua juga.

Secara lebih rinci implementasi PHP2D dari perspektif masyarakat sasarn dapat dijelaskan sebagai berikut:

a. Keterlibatan masyarakat sasaran dalam perencanaan kegiatan meliputi:

- Dalam menyusun rencana kegiatan mahasiswa yakni penyusunan proposal.

- Dalam survey demografi, pendataan kondisi belajar anak-anak dan fasilitas belajar yang ada di desa

- Wawancara tentang kebutuhan pembelajaran mereka

- Dengan seksama membantu mengantar tim ke banjarbanjar yang akan dipasang internet dan fasilitas perpustakaan

b. Hal-hal apa saja yang diterima masyarakat sasaran selama kegiatan pemberdayaan masyarakat oleh mahasiswa dengan nama PHP2D meliputi:

- Fasilitas pembelajaran yang terdiri dari rak buku, meja kerja lengkap dengan bukunya.

- Pemasangan internet pada masing-masing banjar

- Televisi untuk media akses internet

- Pendampingan yang dilakukan oleh mahasiswa berhasil meningkatkan animo anak- anak untuk belajar medkipun Covid 19.

c. Penilaian masyarakat sasaran tentang manfaat kegiatan pemberdayaan masyarakat oleh mahasiswa atau PHP2D meliputi:

- Masyarakat menerima dengan baik, bersyukur anak-anak sekolah bisa belajar dengan mengakses internet gratis di setiap banjar.

- Masyarakat mendapatkan manfaat yang besar bagi anakanak sekolah yang tidak bisa belajar dimasa Pandemic Covid 19.

- Biaya kuota internet yang menjadi beban keluarga juga berkurang.

- Atmosphire giat belajar berkembang di kalangan anakanak

d. Jumlah kelompok yang merasakan manfaat kegiatan mahasiswa (PHP2D)

- Masyarakat desa yang terdiri dari empat banjar / RW di masing-masing banjar mendapatkan satu set fasilitas belajar.

- Anak-anak sekolah pada masing-masing banjar yang terdiri dari 25-30 orang anak sekolah.

- Kelompok orang tua murid yang sangat terbantu dalam mendidik anak-anaknya selama kegiatan belajar di sekolah ditutup.

- Kelompok aparat desa dan banjar mendapat partner yang potensial dalam melaksanakan program ini.

- Pemangku kepentingan yang lain seperti PEMDA dan 
Camat mendapat insirasi untuk mengembangkan program ini pada desa-desa lain.

e. Perubahan apa saja yang dirasakan di hati bapak/ibu (masyarakat) setelah mengikuti kegiatan pemberdayaan masyarakat oleh mahasiswa? (kegiatan PHP2D):

- Wawasan anak-anak semakin terbuka

- Anak-anak ceria, mampu berkomunikasi dengan baik, mendapat perhatian yang lebih focus dari mahasiswa pendamping dibandingkan belajar dengan orang tua.

- Cara bekajar yang serba cepat dan akurat melahirkan generasi milenial yang handal.

- Iklim akademik pembelajaran di desa yang kental, diharapkan mampu membangun perubahan mindset yang maksimal

f. Peran masyarakat dalam pelaksanaan kegiatan pemberdayaan oleh mahasiswa ini? ( PHP2D) meliputi:

- Memberi dukungan phisik dan moral bagi mahasiswa yang menjadi pendamping anakanak belajar.

- Memotivasi anak di rumah mereka masing-masing untuk bersemangat kuliah agar sukses.

- Memberikan dukungan materila berupa snack untuk belajar anak-anak, melalui ibu-ibu PKK desa.

g. Prosentase Partisipasimasyarakat dalam kegiatan pemberdayaan oleh mahasiswa atau kegiatan PHP2D ini dan bentuk partisipasinya meliputi:

- Prosentase partisipasi masyarakat mencapai $100 \%$.

- Membantu mahasiswa menyiapkan meja kursi belajar dan peralatan belajar lainnya

- Memotivasi para orang tua murid yang memiliki anak sekolah SD dan SMP agar mengajak putri-putrinya turut belajar

h. Harapan masyarakat terhadap kegiatan pemberdayaan masyarakat oleh mahasiswa (PHP2D):

- Pemberdayaan ini harus dilanjutkan lagi tahun depan meskipun sudah habis periodenya

- Pemberdayaan ini juga perlu dikembangkan pada aspek lain seperti desa wisata dan pengembangan UMKM

\section{Tingkat Keberhasilan Program}

Berdasarkan hasil wawancara dengan tokoh masyarakat, orang tua murid dan kepala desa Cepaka, kami dapat simpulkan bahwa kegiatan ini secara menyeluruh berjalan dengan baik dan memberi manfaat yang positif bagi kalangan masyarakat. Berdasarkan indikator-indikator yang ditetapkan maka dapat dijelaskan secara rinci sesuai dengan tabel berikut ini: 
Tabel 3

Tingkat Keberhasilan Program

\begin{tabular}{|c|c|c|c|c|}
\hline NO & ASPEK & INDIKATOR & $\begin{array}{l}\text { SEBELUM } \\
\text { PHP2D }\end{array}$ & $\begin{array}{l}\text { SETELAH } \\
\text { PHP2D }\end{array}$ \\
\hline 1 & $\begin{array}{l}\text { Perubahan perilaku } \\
\text { (Diuji dengan } \\
\text { pemberian quiz, test, } \\
\text { wawancara dan } \\
\text { games) }\end{array}$ & $\begin{array}{l}\text { Pengetahuan } \\
\text { Sikap mental } \\
\text { (kesadaran) } \\
\text { Keterampilan }\end{array}$ & $\begin{array}{l}\text { Apatis dan } \\
\text { slow respect }\end{array}$ & $\begin{array}{l}\text { Tercapai } \\
\text { "Kooperatif, smart } \\
\text { dan trampil." }\end{array}$ \\
\hline 2 & $\begin{array}{l}\text { Perubahan physik } \\
\text { (Check list peralatan } \\
\text { yang terpasang di } \\
\text { objek) }\end{array}$ & $\begin{array}{l}\text { Akses internet } \\
\text { terpasang } \\
\text { Perpustakaan } \\
\text { terkelola } \\
\text { Pembelajaran } \\
\text { terlaksana } \\
\text { Mahasiswa menjadi } \\
\text { guru. }\end{array}$ & $\begin{array}{l}\text { Tata kelola } \\
\text { yang minim } \\
\text { dan terbatas }\end{array}$ & $\begin{array}{l}\text { Tercapai } \\
\text { "Tata kelola } \\
\text { pembelajaran SD di } \\
\text { desa yang baik." }\end{array}$ \\
\hline 3 & $\begin{array}{l}\text { Kelembagaan } \\
\text { (Diuji dengan } \\
\text { terbentuknya } \\
\text { kelembagaan di } \\
\text { masyarakat desa) }\end{array}$ & $\begin{array}{l}\text { Terbentuk tim } \\
\text { perpustakaan } \\
\text { Terbentuk tim } \\
\text { "guru" mahasiswa } \\
\text { pembimbing di } \\
\text { rumah belajar }\end{array}$ & $\begin{array}{l}\text { Tidak ada } \\
\text { lembaga yang } \\
\text { mengelola }\end{array}$ & $\begin{array}{l}\text { Tercapai } \\
\text { "Lembaga yg } \\
\text { mengelola jelas } \\
\text { berkesinambungan" }\end{array}$ \\
\hline 4 & $\begin{array}{l}\text { Rancangan program } \\
\text { tindak lanjut. }\end{array}$ & $\begin{array}{l}\text { Kaderisasi personil. } \\
\text { Penambahan } \\
\text { personil untuk } \\
\text { kegiatan baru lain. }\end{array}$ & $\begin{array}{l}\text { Tidak ada tim } \\
\text { dan kaderisasi }\end{array}$ & $\begin{array}{l}\text { Tercapai } \\
\text { "Dilanjutkan oleh } \\
\text { kader baru " }\end{array}$ \\
\hline 5 & $\begin{array}{l}\text { Korelasi mata } \\
\text { kuliah } \\
\text { (Diuji dengan quiz, } \\
\text { test bagi mahasiswa } \\
\text { pada aspek content } \\
\text { implementasi mata } \\
\text { kuliah }\end{array}$ & $\begin{array}{l}\text { Pemahaman mata } \\
\text { kuliah } \\
\text { Capaian } \\
\text { pembelajaran mata } \\
\text { kuliah } \\
\text { Peningkatan soft } \\
\text { skill }\end{array}$ & $\begin{array}{l}\text { Implementasi } \\
\text { mata kuliah } \\
\text { secara teoritis }\end{array}$ & $\begin{array}{l}\text { Tercapai } \\
\text { Implementasi MK } \\
\text { KKN, KomBis dan } \\
\text { Kewirausahaan. }\end{array}$ \\
\hline
\end{tabular}

\section{KESIMPULAN}

Berdasarkan hasil evaluasi dan capaian indikator, maka dapat disimpulkan bahwa program PHP2D berjudul Optimalisasi Balai Banjar Sebagai Rumah Belajar Masa Pandemic Covid 19 di Desa Cepaka terlaksana dengan baik. Seluruh masyarakat sasaran yang menjadi objek pelaksanaan program merasakan manfaat program ini dan berharap program dapat dilanjutkan kembali oleh mahasiswa UNTRIM pada tahun 2021. Mahasiswa juga mendapat pengalaman berharga dari pembelajaran ini dan menjadi lebih bertanggung jawab dalam melaksanakan program kerja di desa.

Saran yang konkrit atas pelaksanaan program ini adalah:

1) Kegiatan membangun desa membutuhkan kolaburasi yang baik antara mahasiswa dengan aparat desa maupun masyarakat. Agar kegiatan berjalan dengan baik, dibutuhkan mediasi oleh dosen sehingga implementasi program bisa lebih cepat. 
2) Penjadwalan pencairan dana dan jadwal realisasi kegiatan terpaut cukup lama, membutuhkan talangan dana dari universitas atau bahkan bila tidak ditalangi, maka terjadi kesan keterlambatan dalam eksekusi.

3) Mengingat jumlah desa yang terbelakang dengan berbagai keterbatasan sangatlah banyak, KEMDIKBUD harus lebih banyak membuka peluangpeluang mengabdi di desa. Prosentase pendanaan proposal yang diajukan mahasiswa perlu ditingkatkan.

\section{UCAPAN TERIMA KASIH}

Ucapan terima kasih yang sebesar-besarnya kami sampaikan kepada Universitas Triatma Mulya yang telah berkontribusi memberikan dukungan dana, material dan mengimplementasikan program PHP2D ini. Ucapan terima kasih yang dalam pula disampaikan kepada Menteri Pendidikan dan Kebudayaan yang telah mencetuskan program dan mendanai PHP2D ini. Melalui ajang ini mahasiswa berlomba kreatif dan berkontribusi memajukan desa. Ucapan terima kasih juga kami sampaikan kepada segenap aparat Desa Cepaka, masyarakat, orang tua siswa dan anak-anak Desa Cepaka yang antusis belajar di balai banjar.

\section{Poster PHP2D}

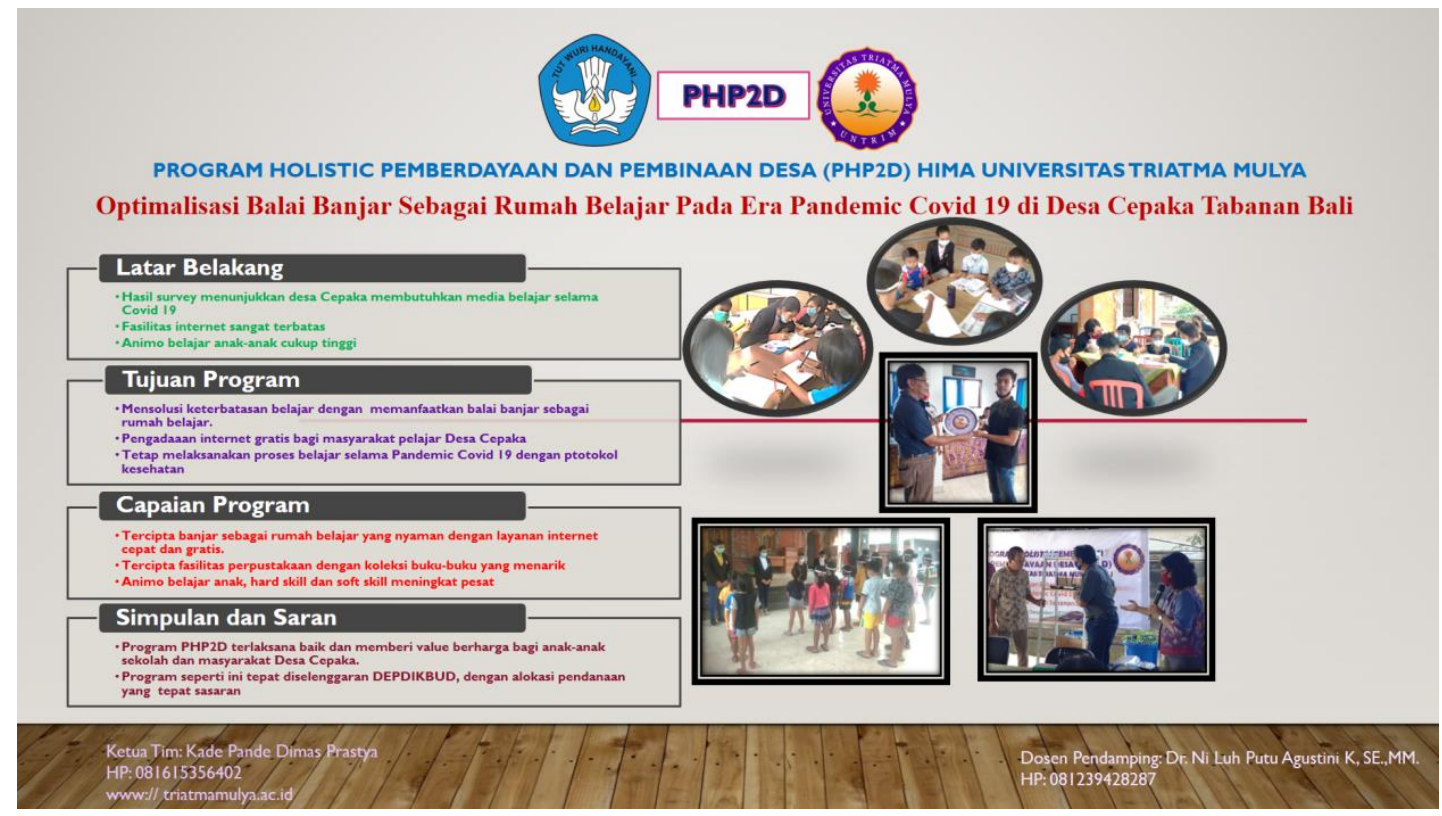

YOUTUBE CHANNEL: https://youtu.be/ml2r3JS2vjU 